\title{
Early neonatal mortality trend in adolescent pregnant women in the State of São Paulo, Brazil, from 1996 to 2017
}

\author{
Adriana Gonçalves de Oliveira ${ }^{1,2,3}$, Hugo Macedo $\mathrm{Jr}^{1}$, Edigê Felipe de Sousa Santos ${ }^{1,4}$, Claudio Leone ${ }^{1}$, \\ Francisco Naildo Cardoso Leitão ${ }^{1}$, Renata M. M. Pimentel ${ }^{1}$, Luiz Carlos de Abreu ${ }^{5,6,7}$, \\ Rubens Wajnsztejn ${ }^{1,3}$
}

${ }^{1}$ Laboratório de Delineamento de Estudos e Escrita Científica, Centro Universitário Saúde ABC, Santo André, SP, Brasil; ${ }^{2}$ Serviço de Neonatologia, Hospital Municipal de Diadema, SP, Brasil; ${ }^{3}$ Programa de Pós-graduação em Ciências da Saúde, Centro Universitário Saúde ABC, Santo André, SP, Brasil; ${ }^{4}$ Departamento de Epidemiologia, Faculdade de Saúde Pública da Universidade de São Paulo, Brazil; ${ }^{5}$ Adjunct Professor, School of Medicine, University of Limerick, Limerick, Ireland; ${ }^{6}$ Professor Titular, Departamento de Educação Integrada em Saúde e Programa de Pós-Graduação em Saúde Coletiva, Universidade Federal do Espírito Santo, ES, Brasil; ${ }^{7}$ Orientador Pleno, Programa de Pós-graduação em Ciências Médicas, Faculdade de Medicina da Universidade de São Paulo, São Paulo, Brazil

Contributions: (I) Conception and design: AG de Oliveira, H Macedo Jr, EFS Santos, C Leone, LC de Abreu; (II) Administrative support: C Leone, H Macedo Jr, LC de Abreu; (III) Provision of study materials: EFS Santos; (IV) Collection and assembly of data: EFS Santos, FNO Leitão, AG de Oliveira; (V) Data analysis and Interpretation: R Wajnsztejn, FNO Leitão, EFS Santos, RMM Pimentel; (VI) Manuscript writing: All authors; (VII) Final approved manuscript: All authors.

Correspondence to: Luiz Carlos de Abreu. Programa de Pós-Graduação em Saúde Coletiva. Universidade Federal do Espirito Santo, Av. Marechal Campos, 1468, 29043-900 - Vitória - ES, Brasil. Email: luiz.abreu@ufes.br.

Background: The Infant mortality rate indicates the quality of life of a population. Infant mortality has two important components: neonatal mortality, divided into early and late and post-neonatal mortality. The more developed a country is and the greater its population's well-being, the greater the weight of the neonatal component on infant mortality. In addition several factors may determine or be associated with the occurrence of infant deaths including maternal age. The teenage pregnancy rates in Latin America and the Caribbean remain the second highest in the world, In Brazil, between 2010 and 2015, for every thousand adolescents between 15 and 19 years old, about 69 became pregnant and gave birth to their babies. Thus, the objective of this study is to evaluate the trend of Early Neonatal Mortality Rates in children of pregnant adolescents, which occurred in the period 1996-2017, in the state of São Paulo, Brazil, according to the maternal age group.

Methods: This is an ecological study of time series using official mortality data obtained from the Mortality Information System and live birth data obtained from the Live Birth Information System. Deaths of newborns aged between zero and six complete days were collected by place of residence. The trends in rates per 1,000 live births were calculated by Prais-Winsten regression, obtaining their annual percentage change (VPA) and the respective $95 \%$ confidence intervals, analyzed by age group. All analyzes were processed using the STATA 15.1 software.

Results: In the state of São Paulo, between 1996 and 2017, 16,161 deaths were reported in children from zero to six days old and 2,320,584 live births in mothers aged 10-19 years, living in the state of São Paulo, Brazil. Of this total, it was observed that the early neonatal mortality rate decreased until the year 2005-2006, remained stationary after, and was higher in newborns of mothers aged 10-14 years (13.18 per 1,000) compared to mothers between $15-19$ years (6.75 per 1,000).

Conclusions: In conclusion, although the early neonatal mortality rate showed a significant decreasing trend until approximately 2005, it remained stables after that.

Keywords: Perinatal mortality; pregnant women adolescent; death certificates; time series studies; risk factors

Submitted Dec 11, 2020. Accepted for publication Apr 05, 2021.

doi: $10.21037 /$ tp-20-438

View this article at: http://dx.doi.org/10.21037/tp-20-438

(c) Translational Pediatrics. All rights reserved. 


\section{Introduction}

Infant mortality is a public health problem. About one-third of these deaths occur on the first day and almost threequarters only in the first week of life (1).

Newborns are dying at "alarmingly high" rates in developing countries, affected by conflict or weak institutions (2). The Infant Mortality Rate (IMR) is a sensitive indicator of the quality of care during pregnancy and birth (2).

According to the Ministry of Health, early neonatal death is defined as the ratio of total newborn deaths occurring in the first week of life (from zero to $6^{\text {th }}$ complete days of life) per one thousand live births, per year, in the resident population in a given geographical area (3).

Most childhood deaths are concentrated in the first year of life, especially in the first month (early and late neonatal mortality). There is high participation of perinatal causes, such as prematurity and anoxia, that highlight the importance of factors related to pregnancy, delivery, and the newborn in the field of perinatology, showing that there is still room for general preventive actions through quality health care (4-7).

Several factors, traditionally known, may determine or be associated with the occurrence of infant deaths: prematurity, low birth weight, severe asphyxia, twinning, congenital malformations, male gender, socioeconomic conditions, maternal age, gestational age, and access and quality of prenatal care $(4,7)$.

Worldwide, there are approximately 16 million pregnant women in the age group between 15 and 19 years of age; and 2 million adolescents under the age of 15 . The world teenage pregnancy rate is estimated at 46 births per 1,000 girls, while in absolute numbers, this represents 400 thousand cases per year. Annually about $18 \%$ of Brazilians born are children of teenage mothers. 15.3 baby deaths are recorded for every 1,000 live births of young mothers (up to 19 years old) - one of the highest infant mortality (8). For Rios, Willians and Aiello (9), teenage mothers seek less prenatal care, haven't enough family support, and their children have a higher risk of low birth weight, prematurity, morbidity, and mortality (9).

It is known that prematurity can generate complications in the newborn and that they are more prone to present chronic diseases during their adult life. However, the mechanisms of prematurity and the mother-child relationship are not yet fully elucidated in literature (9).
There are few studies evaluating developmental changes and their causal factors of neonatal mortality (9).

Thus, understanding these problems of access to health care in pregnant women is essential, not only for the evolution of pregnancy but also to minimize the impact on the health of the next generation.

In addition, neonatal deaths are an important component of infant mortality in Brazil, with asphyxia, low birth weight, respiratory problems in the neonatal period, infections, and prematurity attributed to various situations linked to the quality of preventive measures (10).

Thus, the objective of this study is to evaluate the trend of Early Neonatal Mortality Rates in children of pregnant adolescents, which occurred in the period 1996-2017, in the state of São Paulo, Brazil, according to the maternal age group.

We present the study in accordance with the MDAR reporting checklist (available at: http://dx.doi.org/10.21037/ tp-20-438).

\section{Methods}

\section{Type of study}

This is an ecological study of time series using official mortality data obtained from the Mortality Information System (SIM). The data of live births were obtained from the Live Birth Information System (SINASC). Both systems make information available on the website of the SUS Computer Department (DATASUS), maintained by the Brazilian Ministry of Health.

\section{Place and period of research}

The analysis unit selected for this study was the state of São Paulo, which has approximately 600 thousand live births per year and an infant mortality rate of $11.19 \%$ o (11.19 per thousand) live births in 2021 (11). The state consists of 644 municipalities (with 41 million inhabitants) and the city of São Paulo (with 12 million inhabitants), the state's capital.

Data of the deaths were collected by place of residence, and it corresponds to the period between January 1, 1996, and December 31, 2017.

\section{Population of the study}

All the deaths that occurred during the early neonatal 
period of pregnant adolescents between 10 and 19 years of age, who were born alive in the state of São Paulo, Brazil, notified through SIM and SINASC were considered.

\section{Database}

Secondary data came from the Mortality Information System (SIM) and the Live Birth Information System (SINASC). Both systems make data available on the website of the SUS Computer Department (DATASUS), an official, free database of information relevant to public health in Brazil and maintained by the Ministry of Health (website: http://datasus1.saude.gov.br/health-information/ tabnet/vital-statistics). All data was completely anonymized before data collection. In addition, this platform is used for planning and evaluating public health policies in Brazil (12). This service started with the registration of data on deaths (vital statistics) and also allowed tabulation of live births. The SIM receives, processes, confers consistency and validity on the primary cause of death recorded in the Death Certificate (13) of more than $96 \%$ of deaths registered in Brazil (14) and has a coverage of $99.8 \%$ over the total number of births in maternity hospitals in the Unified Health System (SUS) network in the city of São Paulo (15). From the SIM, it became possible to capture data on deaths for the construction of health indicators and analysis of time series. SINASC was developed to collect epidemiological data on births reported across the country and also to support interventions related to the health of pregnant women and newborns, as well as monitoring the evolution of the SINASC (16) historical series. For data extraction, TABNET was used, which is a generic public domain tab that allows you to organize data quickly, according to the query you want to tabulate. Then, the files were expanded to .XLS version, and the variables selected for this study were categorized in Microsoft Excel. The data were collected by two independent researchers trained for this task to identify possible discrepancies.

The gestational age (GIS) variable was categorized as follows: <28 GIS; 28-31 GIS; 32-36 GIS; 37-42 GIS; $>42$ GIS.

Thus, it was opted to group the categories of gestational ages under 22 GIS and 22-27 GIS to provide a sufficient number of deaths and provide a better presentation of early neonatal mortality rate. DATASUS constitutes the official free and public health information database of the country, from where the information on deaths and births used in this study was collected (15).

\section{Study variables}

The death of live births between 0 and 6 days of age (yes or no) was the variable of interest in the study. The other variables considered are present in the Death Certificate and Live Birth Declaration, namely: sex (male and female); race/color (white, black, brown, yellow, and indigenous), gestational age (weeks), birth weight (grams), mother's age (age group), mother's education (years of schooling), type of pregnancy (single, double and triple and more) and type of delivery (cesarean and vaginal).

\section{Statistical analysis}

Rate trends were analyzed using the Prais-Winsten regression model (17). Early neonatal mortality trends were calculated, broken down by maternal age, year by year (1996-2017), expressed per 1,000 live births.

This statistical procedure made it possible to estimate: angular coefficient ( $\beta$ ) and $\mathrm{P}$ value (p), considering a $95 \%$ significance level.

The modeling process considered that the dependent variable was the logarithm of the rates, and the independent variable was "the years of the historical series". The annual percentage change (VPA) of the rates was also calculated (18). Next, the Durbin-Watson test was used to scale the existence of first order self-correlation of the time series composed by the annual coefficients, as well as to verify if the correlation was compatible with the hypothesis of regression residues with random distribution.

Thus, it promoted the elaboration of the temporal trend of early neonatal mortality is increasing, decreasing, or stationary, being considered stationary, the trend whose regression coefficient was not significantly different from zero $(\mathrm{P}>0.05)$.

For the visualization of trends, white noise was reduced in the graphs of the historical series, using the technique of central moving averages of order three for trends in early neonatal mortality rates, according to maternal age (19). All the analyses were performed using the STATA 15.1 (2018) program.

\section{Ethical and legal aspects of research}

The study was conducted in accordance with the Declaration of Helsinki (as revised in 2013). This study used secondary data, involving the description and analysis of population data present in public databases. 
Table 1 Early neonatal mortality rate, second year and age of the mother, São Paulo State, Brazil, 1996-2017

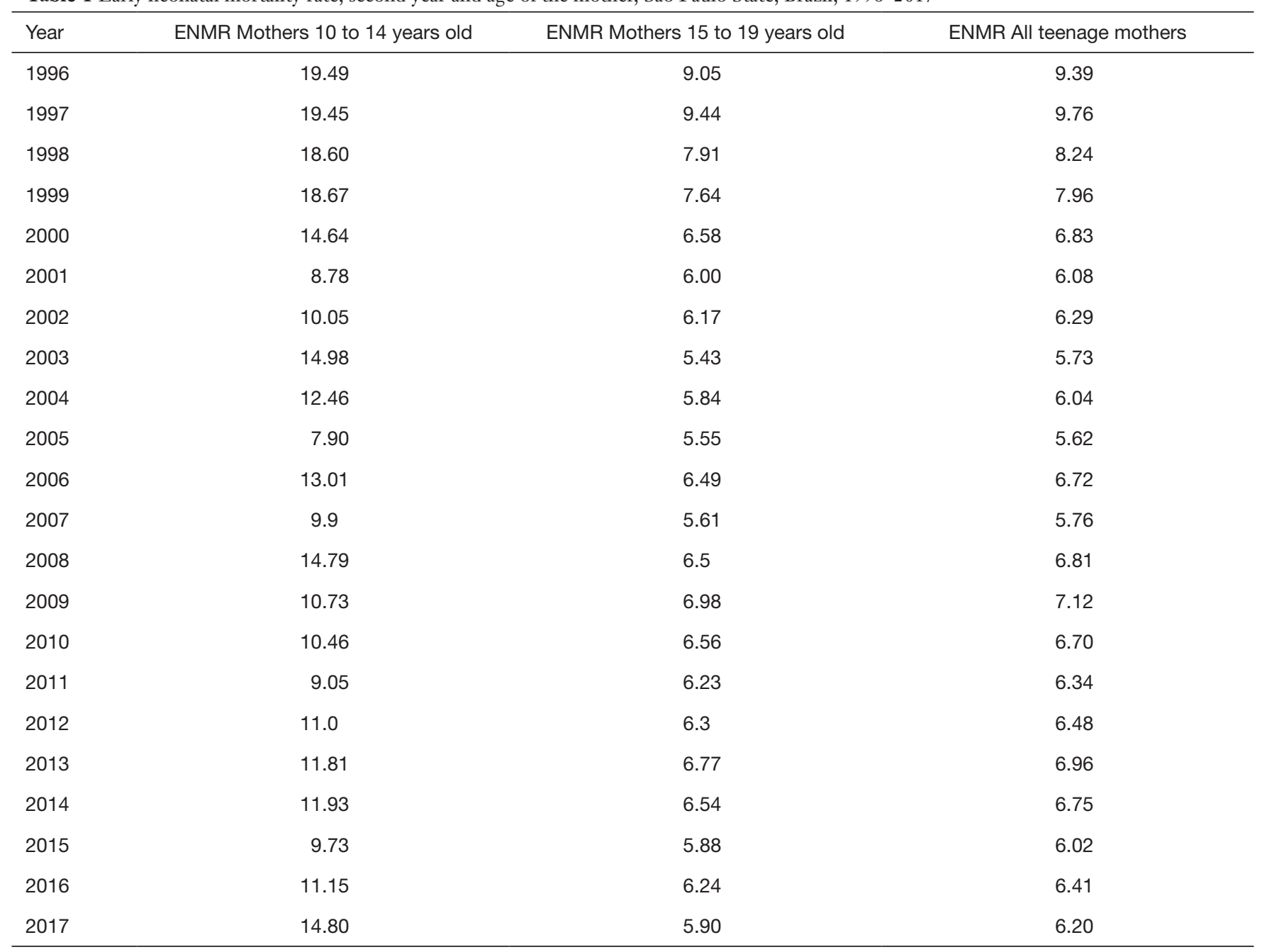

ENMR, early neonatal mortality rate.

Included were those data from the general population and death census, collected from the Mortality Information System. All these sources of information are in the public domain and freely accessible. It should be noted that no information, such as the individual identification of the subjects, was obtained for this study. This eliminates the need for submission to our ethics committee according to resolution CNS 510/2016.

\section{Advantages}

Data obtained from information systems maintained by the Ministry of Health are reliable, especially in the state of São Paulo, where information systems have good quality and completeness (20,21), allowing its use as a feasible tool for the analysis of neonatal deaths.

\section{Results}

From 1996 to 2017 in the state of São Paulo, 16,161 deaths were registered in children from zero to six days of age, and 2,320,584 were born alive to mothers between $10-19$ years of age, living in the state of São Paulo, Brazil.

The Early Neonatal Mortality Rate in the period 1996-2017 ranged from $9.39 \%$ to $6.20 \%$ live births. The reduction in annual rates observed over time was interrupted in 2009, when it was $7.12 \%$ o live births, declining again (Table 1). Most of the deaths, almost 2/3, occurred in the first 24 hours (3.36\%) (Table 2).

From the total of deaths, it was observed that the Early 
Table 2 Characteristics of zero to six-day deaths of newborns of mothers aged 10-19 years living in the state of São Paulo, Brazil, 1996-2017

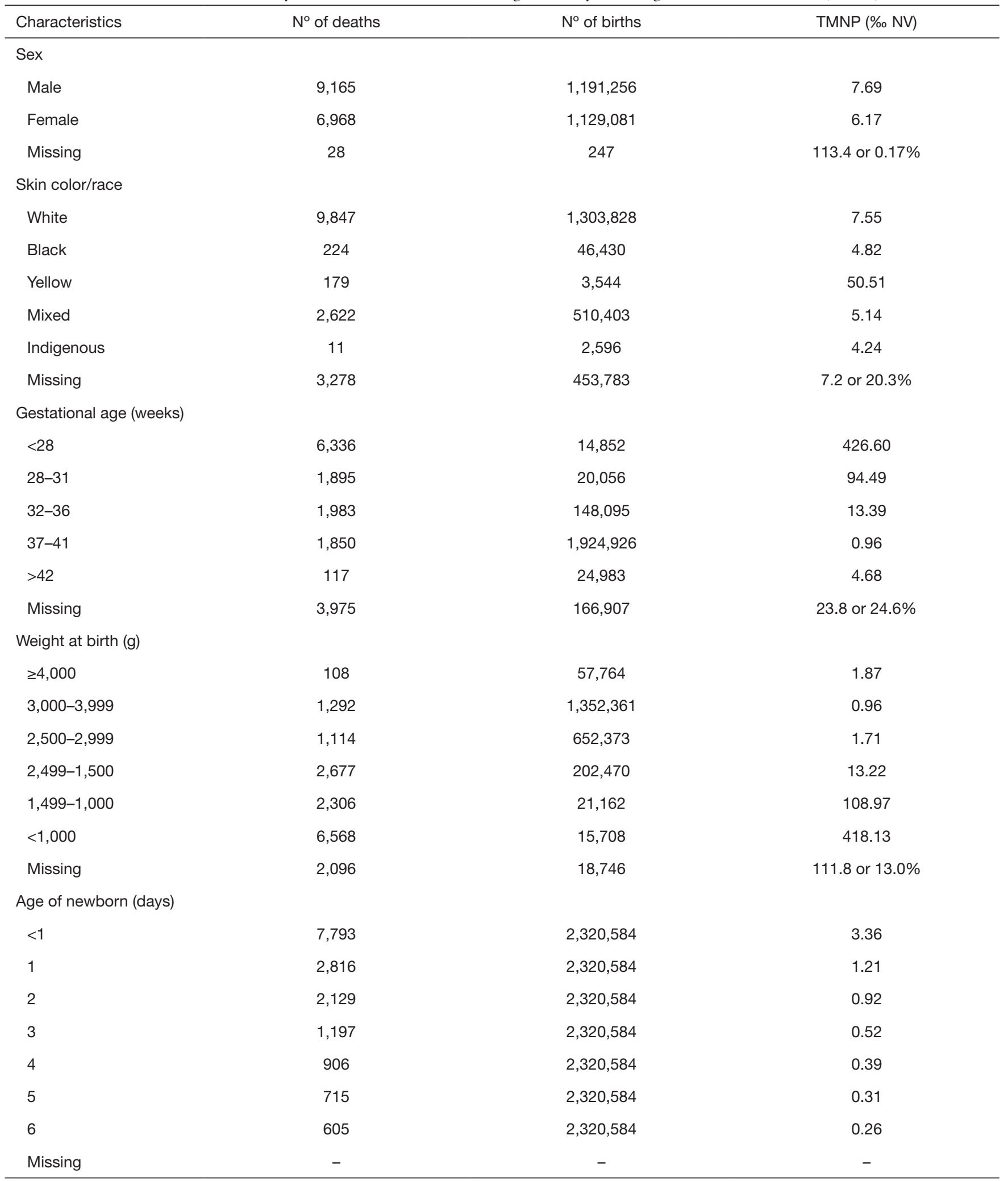

ENMR, early neonatal mortality rate; NV, live births; Missing: ignored or missing data. 
Table 3 Characteristics of mothers aged 10-19 years of zero to six-day deaths of newborns living in the state of São Paulo, Brazil, 1996-2017

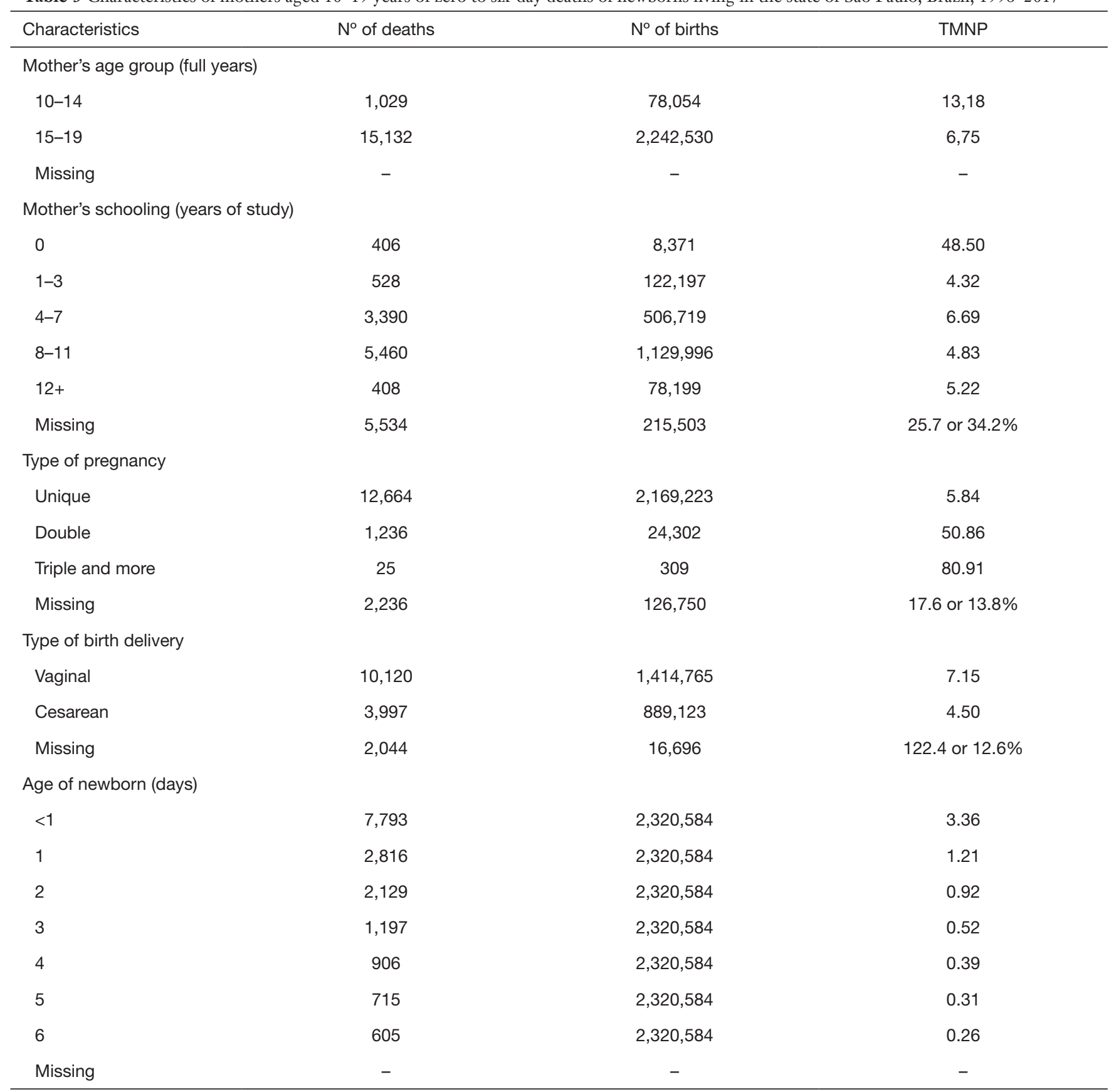

ENMR, early neonatal mortality rate; NV, live births; Missing: ignored or missing data.

Neonatal Mortality Rate (ENMR) was higher in males (7.69\%), in those with yellow skin color $(50.51 \%$ o), in those with a gestational age below 28 weeks (378.60\%), and among those with birth weight less than 1,000 grams (418.13\%o) (Table 2).

As for adolescent mothers, the ENMR was higher among
$10-14$ years old $(13.18 \%$ ) and those without schooling $(48.50 \%)$. As for the type of delivery, early neonatal mortality was more frequent in vaginal deliveries $(7.15 \%$ o) and triple or more pregnancies (80.91\%o) (Table 3).

The Early Neonatal Mortality Rate in children of pregnant adolescents between 10 and 19 years of age in the 


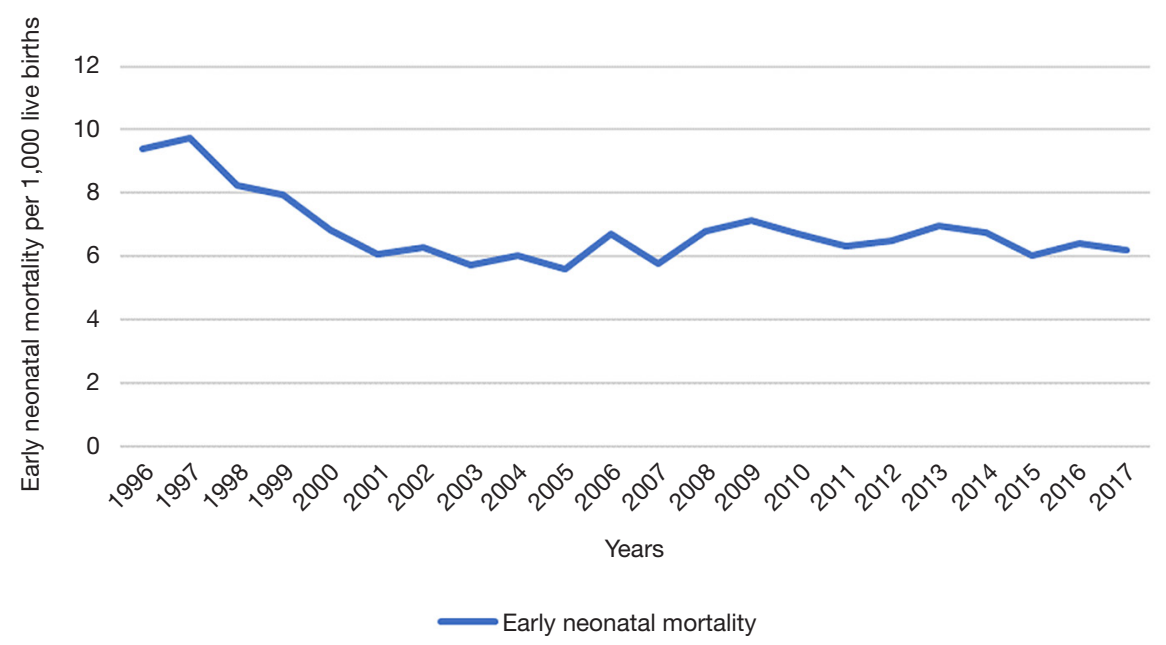

Figure 1 Early neonatal mortality (per thousand live births) of newborns of 10-19 years old mothers living in the state of São Paulo, Brazil in the period 1996-2017.

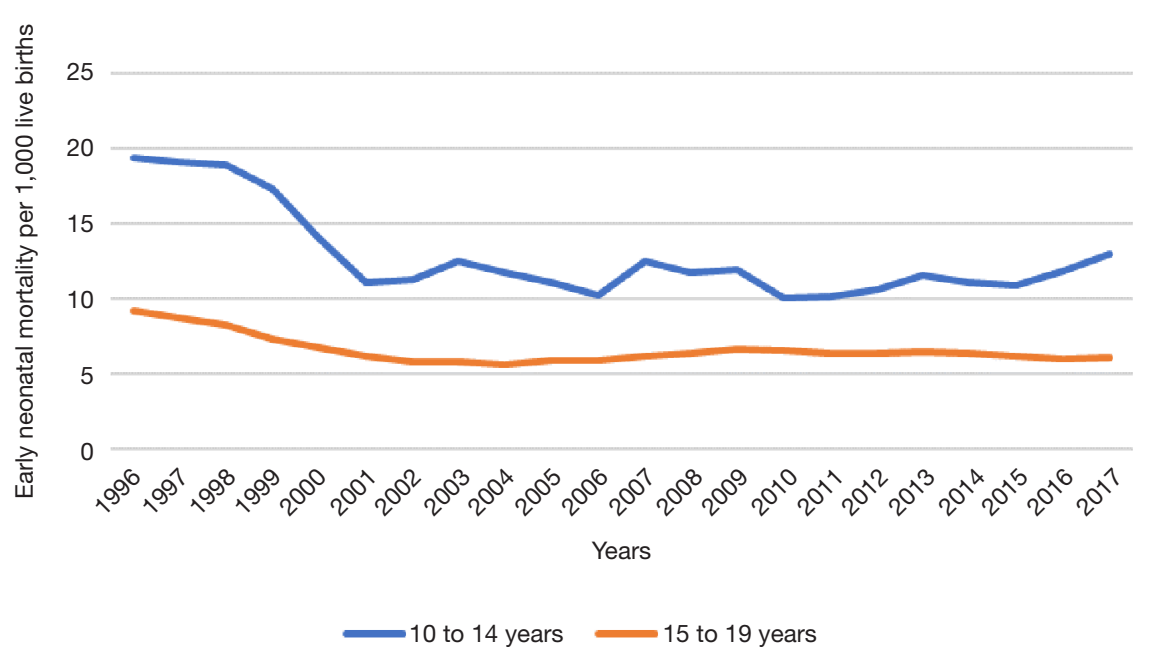

Figure 2 Early neonatal mortality (per thousand live births), according to maternal age, São Paulo State, Brazil in the period $1996-2017$.

State of São Paulo shows a $40 \%$ reduction, evolving from $10 \%$ live births to $6 \%$, between the beginning and the end of the analyzed period (Figure 1).

However, when analyzed in two periods, the evolution of Early Neonatal Mortality Rate (ENMR) appears differently, adolescents aged 10-14 years varied from $19.49 \%$ o to $14.9 \%$ o born alive, while for those aged 15-19 years varied from $9.05 \%$ o to $5.90 \%$ o born alive. After the year 2000, the peak of early neonatal mortality in adolescents aged 10 to 14 years occurred in 2003 (14.98\%o live births) and 2009 for those aged 15 to 19 years (6.98\%o live births) (Figure 2). Highlighting a significant decline between 1996-2006, varying from 6.5\% per year in mothers between $10-14$ years old and $4.3 \%$ per year between 15-19 years old (Table 4).

In the ENMR, specifically in the case of adolescents between 10 and 14 years of age, there was an increase in rates from $10.1 \%$ o to $13 \%$ o born alive between 2010 and $2017(\mathrm{P}=0.003)$ (Figure 3).

\section{Discussion}

The stillbirth rate is an important indicator that reveals health and care conditions during prenatal and childbirth. 
Table 4 Early neonatal mortality trend (per thousand live births), according to maternal age, São Paulo state, Brazil, 1996-2017. Santo André, 2020

\begin{tabular}{|c|c|c|c|c|}
\hline & \multicolumn{4}{|c|}{ Rates according to age group } \\
\hline \multicolumn{5}{|c|}{ Overall period (1996-2017) } \\
\hline $10-14$ & $-0.008(-0.018,0.001)$ & $>0.05$ & $-1.8(-4.1,0.2)$ & Reduction (ns) \\
\hline $15-19$ & $-0.007(-0.014,0.001)$ & $>0.05$ & $-1.6(-3.2,0.2)$ & Reduction (ns) \\
\hline $10-14$ & $-0.029(-0.053,-0.006)$ & $<0.05$ & $-6.5(-11.5,-1.4)$ & Reduction (sig) \\
\hline $15-19$ & $-0.019(-0.033,-0.004)$ & $<0.05$ & $-4.3(-7.3,-0.9)$ & Reduction (sig) \\
\hline \multicolumn{5}{|c|}{$2^{\text {nd }}$ period $(2007-2017)$} \\
\hline $10-14$ & $0.004(-0.011,0.020)$ & $>0.05$ & $0.9(-2.5,4.7)$ & Increase (ns) \\
\hline
\end{tabular}

$\beta$, regression coefficient; $95 \% \mathrm{Cl}$, confidence interval of 95\%; VPC, Annual Percentage Variation; ns, not significant; sig, significant. Mortality Information System Data (SIM). DATASUS - www.datasus.gov.br - Ministry of Health, Brazil.

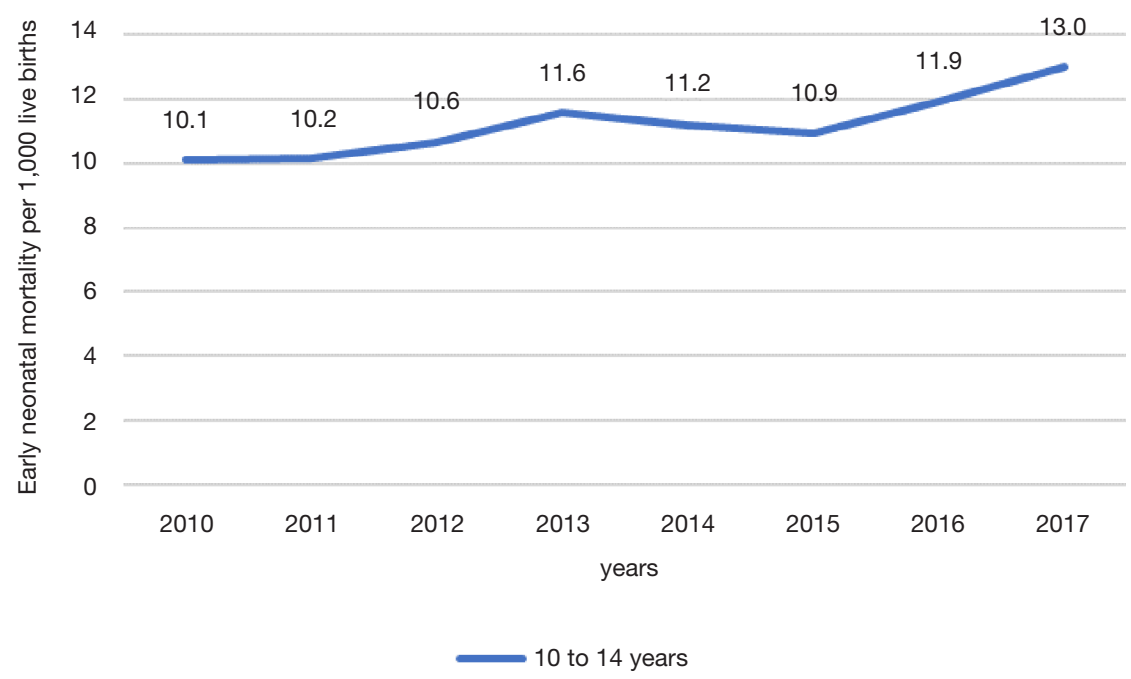

Figure 3 Trend in the Early Smoothed Neonatal Mortality Rate (per thousand live births), second mater $(\mathrm{P}=0.003)$.

However, fetal mortality has received little attention in the Brazilian Public Health scenario (22).

The present study showed a reduction in early neonatal mortality in newborns born from adolescent mothers in the state of São Paulo from 1996 to 2017, a trend that is consistent with that of the infant mortality indicator.

In Brazil, from 1990 to 2012, the infant mortality rate decreased from 47.1 deaths per thousand live births in 1990 to 14.6 deaths per thousand live births in 2012, showing a reduction of approximately $70 \%$ in this period (23).
It is important to note that in 2011 Brazil reached a Child Mortality Rate of 17.7 deaths per thousand live births. From 1990 to 2011, there was a reduction in the difference between the regions with the rate decreasing in all of them. The pace of reduction was more accelerated in the Northeast (reduction of $76 \%$, an average of $6.6 \%$ per year). In 1990 , mortality in the Northeast region was 2.5 times higher than in the South, which was reduced to 1.6 times in 2011 (23).

Andrade et al. (24) noted that the trend in infant mortality rate declined in Rio Branco, Acre, Brazil, in the 
period 1999 to 2015 , but when compared to developed countries, it is still high. The early neonatal component was the one that most contributed to the high value of infant mortality observed during the period in this capital of the Northern region, followed by post- and late neonatal mortalities.

This result may be due to the increase in access to prenatal care, due to the progressive increase in the coverage of family health teams in the state, in addition to the establishment of a network of maternal and child health care in childbirth care named Stork Network (25).

However, when analyzed in two periods, the evolution of Early Neonatal Mortality Rate (ENMR) appears differently, highlighting a greater decline between 1996-2006, varying from $6.5 \%$ per year in mothers between $10-14$ years old and $4.3 \%$ per year between $15-19$ years old.

This result converges with Laurenti et al. (26) analyzed the influence of maternal age on the perinatal mortality rate, identifying a lower coefficient of stillbirth among younger mothers, with an increase in fetal deaths after 35 years of age (25). In Afghanistan, the maternal age of young people under 18 years old or over 35 years old were also considered determinants that influenced early neonatal mortality (27).

In relation to the trend of stillbirth, there was a reduction in the rates of stillbirth and perinatal mortality in the State of São Paulo since 1980. In 1980, the stillbirth rate was 13.4 per thousand in the State, reaching 8.0 per thousand in 2006 (28).

When analyzed the following period, 2007-2017, the mortality trend of live births of women aged 10-14 years showed an increase of $0.9 \%$ per year, while there was a reduction of $0.2 \%$ per year among women aged $15-19$ years, both without statistical significance.

The ENMR of adolescents aged 10-14 years varied from $19.49 \%$ o to $14.9 \%$ o born alive, while for those aged 15-19 years varied from $9.05 \%$ o to $5.90 \%$ o born alive. After the year 2000, the peak of early neonatal mortality in adolescents aged 10 to 14 years occurred in 2003 (14.98\%o live births) and 2009 for those aged 15 to 19 years (6.98 \%o live births).

In the ENMR, specifically in the case of adolescents between 10 and 14 years of age, there was an increase in rates from $10.1 \%$ o to $13 \%$ o born alive between 2010 and $2017(\mathrm{P}=0.003)$.

In the state of São Paulo, reducing neonatal mortality is a major challenge for health services, government, and society, especially as a result of high rates concentrated mainly in the poorest communities and populations. It is noteworthy that deaths on the first day of life correspond to $25-45 \%$ of those in the neonatal period (22), where three main causes of neonatal deaths are: severe infections, complications during childbirth, and premature birth (25), and in low-income countries, this risk is about thirty times higher (29).

From 2007 to 2016, the highest neonatal mortality rates were observed in the North and Northeast regions of Brazil. In all regions, there was a downward trend throughout the period, with an increase in rates in 2016, except for the Southern Region (30).

In the state of São Paulo, it is described that the children of adolescents between 10 and 14 years of age have an Early Neonatal Mortality Rate of $14.80 \%$, while those of adolescents between 15 and 19 years of age have a rate of $5.89 \%$.

Pregnancy in adolescents under 15 years of age is associated with a substantial increase in the risk of infant mortality when compared to older adults, thus indicating the need for specific intervention and prevention actions in different age groups (25). Another potential risk factor reported in this same study is the absence of the father's registration on the birth certificate (31).

Maternal morbidities and inadequate prenatal care are associated with fetal and neonatal death in puerperal women under 16 years of age in the city of Rio de Janeiro and this group, when receiving support from the baby's father during pregnancy, showed a protective effect against post-natal-Christmas. With these findings, they reaffirm the relevance of social and health policies aimed at adolescents and the improvement of prenatal care (32).

The analysis of trends points to a likely improvement in access and/or quality of care for pregnant women and newborns. Salla and Luppi (33) in the trend analysis of the causes of early neonatal infant mortality in the state of São Paulo did not see possible points of intervention in health services to support these trends. The absence of a tendency to reduce deaths preventable by caring for women during childbirth points to a possible weakness in childbirth care (33).

In the analysis of neonatal death, adequate prenatal consultation, as well as being a newborn female are protective factors. Highlighting that the skin color of the black or brown mother, as well as the previous history of being born dead, maternal morbidity, and physical aggression in pregnancy, have increased the risk of neonatal death (32).

In addition, low birth weight and prematurity were corroborated as determinants of neonatal death. The risk 
was higher in the presence of a higher number of previous pregnancies and gestation morbidity (32).

On the other hand, Oliveira, Gama e Silva (32) highlight that teenage pregnancy emerged with a direct effect on post-neonatal death. This finding is at odds with those reported in this study, with a higher percentage of deaths on the first day of life, highlighting that it has a high mortality rate in the early neonatal.

According to Jorge Machado and Hill (34), the most advanced maternal age, birth weight, gestational age, APGAR bulletin, community development (well-being, income level, education) are important predictors of survival in the neonatal period.

Duplessis, Bell and Richards (35), Age and race are independent factors that influence the outcome of pregnancy. The low birth weight, congenital anomalies, and prematurity have an important impact on the risk of child death (35).

The probability of death in the first year of life related to the age of the mother was 71.4 per thousand for adolescents under 15 years of age in relation to the age group of 15-19 years (25.4 per thousand) in the municipality of Maringá, Paraná (36).

In Afghanistan, the determinants that influenced early neonatal mortality were birth weight, multiple pregnancy, shorter birth intervals, younger, under 18, or older, over 35 , maternal ages (27).

A study conducted in eight states in Brazil found that $1 / 5$ of the deaths occurred on the first day of life, with greater frequency in males, indigenous people, multiple pregnancies, birth weights of less than 1,500 g, teenage mothers, and women without schooling. Most of the causes of these deaths could be considered avoidable if there was adequate attention to the woman during pregnancy. The research also points out that, in the State of São Paulo, there was a $29 \%$ reduction in the ENMR, but that this reduction is the smallest when compared with the reduction in late or post-neonatal mortality (7).

The number of teenage pregnant women in public service has increased, as have social, family, and psychological problems. Many teenagers have not prepared themselves to get pregnant; they use illegal drugs, and sometimes they don't even know who their father is. Besides being common to try to hide the pregnancy, following this situation, they do not adhere properly to prenatal care and become more exposed to having a premature birth, a low birth weight/small for gestational age, and to complications after birth.
Socioeconomic indicators are important in the analysis of the determinants of early neonatal mortality, with the mother's education being an indirect indicator of a socioeconomic condition. The present study corroborates this situation because the newborns of uneducated mothers or mothers with fewer years of study had the highest risk of early neonatal death.

Another finding that deserves to be highlighted is the association between multiple and, above all, triple pregnancy and early neonatal mortality, findings that agree with those of Morais Neto and Barros (37).

Historically, it is accepted that live births from multiple pregnancies have a high incidence of low birth weight and prematurity, which are risk factors for early neonatal death (38). Consequently, it is essential that pregnant women with multiple pregnancies are identified early in the prenatal period and referred and assisted in high risk services during the gestational period.

In the variable type of delivery, the data reveal a paradox since the cesarean section shows a lower rate of early neonatal mortality than the normal delivery. It is noteworthy that most births are vaginal. This data must be carefully analyzed since both the International Federation of Gynecology and Obstetrics (FIGO) and the WHO recommend vaginal delivery in any situation where there is no risk for the mother and the baby concept.

In another outcome, prematurity is strongly associated with the risk of death of the newborn. The lower the gestational age week, the higher the rate of early neonatal mortality. A finding that converges with studies conducted around the world (29,39-45) and that remains a challenge since not even current and modern technology can reduce these disastrous data of high early neonatal mortality rates, which impacts on infant mortality rates and does not allow their reduction in Brazil.

Thus, it is essential that multisectoral actions (46), of education and social assistance, as well as targeting the health care of pregnant women as a priority, are urgent and necessary measures, because the improvement of prenatal care associated with the implementation of care support to pregnant women needs to be effective in the complications of pregnancy and childbirth, especially in the population of low-income adolescents, leading to the reduction of clinical problems of the newborn and its greater "susceptibility" to early neonatal death.

Therefore, the use of data generated by information and secondary data systems is essential for the planning of health policies, programs, and actions for the correct 
attention, based on evidence, of the early neonatal mortality situation in the State of São Paulo.

However, studies on mortality have their own limitations when secondary data are analyzed, especially with regard to the validity of identifying the primary cause of death; subjectivity and indetermination of racial classification in Brazil, reflecting less homogeneous criteria (47). In addition to the variable race/color being poorly filled in the death certificates, with a relatively large proportion $(20.3 \%)$ of data missing (48). It should be emphasized that the secondary data are official (46) and come from the Ministry of Health, and even containing possible sub-notifications, are the data available for the elaboration of public policies, and as such should be considered.

The analysis of avoidable deaths for a specific cause is an excellent resource to evaluate the resoluteness of maternal and child health services, in addition to providing estimates that assist in decision making and public policy planning. It is believed that quality prenatal care and adequate attention to delivery and the newborn can prevent most deaths on the first day of life. Knowing the evolution of the child mortality rate can favor the decision making of public health policies to ensure better care during prenatal, childbirth, and puerperium.

In conclusion, the trend of early neonatal mortality rates in pregnant adolescents remained stable in the state of São Paulo in the period evaluated.

\section{Acknowledgments}

Funding: The viability of the article is due to the Project Acre - Health in the Western Amazon, through the Interinstitutional agreement between SESACRE/UFAC/ FMABC (Process nº. 007/2015).

\section{Footnote}

Reporting Checklist: The authors have completed the MDAR reporting checklist. Available at: http://dx.doi.org/10.21037/ tp-20-438

Peer Review File: Available at: http://dx.doi.org/10.21037/tp20-438

Conflicts of Interest: All authors have completed the ICMJE uniform disclosure form (available at: http://dx.doi. org/10.21037/tp-20-438). The authors have no conflicts of interest to declare.
Ethical Statement: The authors are accountable for all aspects of the work in ensuring that questions related to the accuracy or integrity of any part of the work are appropriately investigated and resolved. This study used secondary data, involving the description and analysis of population data present in public databases. Included were those data from the general population and death census, collected from the Mortality Information System. All these sources of information are in the public domain and freely accessible. It should be noted that no information, such as the individual identification of the subjects, was obtained for this study. This eliminates the need for submission to our ethics committee according to resolution CNS $510 / 2016$. The study was conducted in accordance with the Declaration of Helsinki (as revised in 2013).

Open Access Statement: This is an Open Access article distributed in accordance with the Creative Commons Attribution-NonCommercial-NoDerivs 4.0 International License (CC BY-NC-ND 4.0), which permits the noncommercial replication and distribution of the article with the strict proviso that no changes or edits are made and the original work is properly cited (including links to both the formal publication through the relevant DOI and the license). See: https://creativecommons.org/licenses/by-nc-nd/4.0/.

\section{References}

1. Brasil, Fundação Abrinq. "Um Brasil para as Crianças A Sociedade Brasileira e os Objetivos do Milênio para a Infância e a Adolescência" [Internet]. Brasil, 2004. [cited 2020 Nov 15]; Available online: https://www.fadc.org.br/ sites/default/files/2018-12/Relatorio-Um-Brasil-Para-ASCriancas_e_Adolescente_I.pdf

2. UNICEF. Levels and Trends in Child Mortality. United Nations Inter-Agency Group for Child Mortality Estimation (UN IGME), [Internet] Report 2019 [cited 2020 Jun 15]; Available online: https://www.unicef.org/ brazil/comunicados-de-imprensa/mortalidade-materna-ena-infancia-mulheres-e-criancas-estao-sobrevivendo-cadavez-mais

3. Brasil. Ministério da Saúde. Secretaria de Vigilância e Saúde. Departamento de Análise de Saúde e Vigilância de Doenças não-transmissíveis. [Internet]. [cited 2020 Nov 15]; 2020. Available online: http://svs.aids.gov.br/ dantps/centrais-de-conteudos/paineis-de-monitoramento/ mortalidade/infantil-e-fetal/

4. Schoeps D, Almeida MF, Alencar GP, et al. Fatores de 
risco para mortalidade neonatal precoce. Rev Saude Publica 2007;41:1013-22.

5. Cohen DA, Farley TA, Masson K. Why is poverty unhealthy? Social and physical mediators. Soc Sci Med 2003;57:1631-41.

6. Gama SGN, Szwarcwald CL, Leal MC. Experiência de gravidez na adolescência, fatores associados e resultados perinatais entre puérperas de baixa renda. Cad Saude 2002;18:153-61.

7. Teixeira JAM, Araujo WRM, Maranhão AGK, et al. Mortalidade no primeiro dia de vida: tendências, causas de óbito e evitabilidade em oito Unidades da Federação brasileira, entre 2010 e 2015. Epidemiologia e Serviços de Saúde 2009;28.

8. WHO, PAHO, UNFPA and UNICEF. Accelerating progress toward the reduction of adolescent pregnancy in Latin America and the Caribbean. [Internet]. Report of a technical consultation. 2017 [cited 2020 Aug 29]; Available online: https://iris.paho.org/ bitstream/handle/10665.2/34493/9789275119761-eng. pdf? sequence $=1$ \&isAllowed $=y \& u a=1$.

9. Rios KSA, Williams LCA, Aiello ALR. Gravidez na adolescência e impactos no desenvolvimento infantil. Adolesc Saude 2007;4:6-11.

10. da Silva APM, Gois RP. Factors related to death hospital newborn. Rev Med UFC 2016;56:16-20.

11. Instituto Brasileiro de Geografia e Estatística (IBGE). Indicadores IBGE [Internet] [cited $2020 \mathrm{Jul}$ 29]; Available online: https://cidades.ibge.gov.br/

12. de Moraes BH, de Abreu LC, Bezerra IMP, et al. Incidence of hospitalization and mortality due to stroke in young adults, residents of developed regions in Brazil, 2008-2018. PLoS One 2020;15:e0242248.

13. Santos EFS, Antunes JLF. Fatores associados à falta de assistência hospitalar nos óbitos por doença cerebrovascular, São Paulo, Brasil: análise comparativa entre 1996-1998 e 2013-2015. Cad Saude Publica 2020;36:e00227718.

14. Adami F, Figueiredo FW, Paiva Lda S, et al. Mortality and Incidence of Hospital Admissions for Stroke among Brazilians Aged 15 to 49 Years between 2008 and 2012. PLoS One 2016;11:e0152739.

15. Aquino BE, Ramos VES, Freitas M, et al. Cobertura, completude e confiabilidade das informações do Sistema de Informações sobre Nascidos Vivos de maternidades da rede pública no município de São Paulo, 2011. Epidemiol Serv Saúde 2018;27:e201712811.

16. Calderon MG, Santos EFS, Abreu LC, et al. Increasing prevalence, time trend and seasonality of gastroschisis in São Paulo state, Brazil, 2005-2016. Sci Rep 2019;9:14491.

17. Antunes JLF, Cardoso MRA. Uso da análise de séries temporais em estudos epidemiológicos. Epidemiologia e Serviços de Saúde 2015;24:565-76.

18. Antunes JLF, Waldman EA. Trends and spatial distribution of deaths of children aged 12-60 months in São Paulo. Bull World Health Organ 2002;80:391-8.

19. Perea LME, Peres MA, Boing AF, Antunes JLF. Trend of oral and pharyngeal cancer mortality in Brazil in the period of 2002 to 2013. Rev Saude Publica 2018;52:10.

20. Correia LOS, Padilha BM, Vasconcelos SML. Métodos para avaliar a completitude dos dados dos sistemas de informação em saúde do Brasil: uma revisão sistemática. Revista Ciência Saúde Coletiva 2014;19:4467-78.

21. Laurenti R, Mello-Jorge MHP, Gotlieb SLD. A confiabilidade dos dados de mortalidade e morbidade por doenças crônicas não-transmissíveis. Ciênc Saúde Coletiva 2004;9:909-20.

22. Cecatti JG, Aquino MMA. Causas e fatores associados ao óbito fetal. Reva de Ciênc Méd 1988;7:43-8.

23. Brasil. Ministério da Saúde. Portal Brasil. ONU: Brasil cumpre meta de redução da mortalidade infantil. [Internet] 2015. [cited 2020 Aug 25]; Available online: http://www. brasil.gov.br/cidadania-e-justica/2015/09/onu-brasilcumpre-meta-de-reducao-da-mortalidade-infantil

24. Andrade AM, Ramalho AA, Opitz SP, et al. Anomalias congênitas em nascidos vivos. Rev Bras Promoç Saúde 2017;30:1-11.

25. Lawn JE, Cousens S, Zupan J; Lancet Neonatal Survival Steering Team. 4 million neonatal deaths: When? Where? Why? Lancet 2005;365:891-900.

26. Laurenti R, Buchalla CM. Estudo da morbidade e mortalidade perinatal em maternidades: II - Mortalidade perinatal segundo o peso ao nascer, idade materna, assistência pré-natal e hábito de fumar da mãe. Rev Saude Publica 1985;19:225-32.

27. Kibria GMA, Burrowes V, Choudhury A, et al. Determinants of early neonatal mortality in Afghanistan: an analysis of the Demographic and Health Survey. Global Health 2018;14,47.

28. Camargo ABM. A natimortalidade e a mortalidade perinatal em São Paulo. São Paulo em Perspectiva, São Paulo, Fundação Seade 2008; 22(1):30-47. SEADE. Available online: http://www.seade.gov.br

29. Oza S, Cousens SN, Lawn JE. Estimation of daily risk of neonatal death, including the day of birth, in 186 countries in 2013: a vital-registration and modelling-based study. 
Lancet Glob Health 2014;2:e635-e644.

30. Brasil. Ministério da Saúde. Secretaria de Vigilância em Saúde. Departamento de Vigilância de Doenças e Agravos não Transmissíveis e Promoção da Saúde. Saúde Brasil 2018 uma análise de situação de saúde e das doenças e agravos crônicos: desafios e perspectivas/Ministério da Saúde, Secretaria de Vigilância em Saúde, Departamento de Vigilância de Doenças e Agravos Não Transmissíveis e Promoção da Saúde - Brasília: Ministério da Saúde, 2019. 424 p. il.

31. Phipps MG, Blume JD, DeMonner SM. Young maternal age associated with increased risk of postneonatal death. Obstet Gynecol 2002;100:481-6.

32. Oliveira EFV, Gama SGN, Silva CMFP. Gravidez na adolescência e outros fatores de risco para mortalidade fetal e infantil no Município do Rio de Janeiro, Brasil. Cad Saude Publica 2010;26:567-78.

33. Salla A, Luppi CG. Tendencia das mortes evitaveis ate o 6 dia de vida no Estado de sao Paulo - 2008 a 2017. Rev Saude Publica 2020;54:132.

34. Machado CJ, Hill K. Maternal, neonatal and community factors influencing neonatal mortality in Brazil. J Biosoc Sci 2005;37:193-208.

35. DuPlessis HM, Bell R, Richards T. Adolescent pregnancy: Understanding the impact of age and race on outcomes. J Adolesc Health 1997;20:187-97.

36. de Souza RK, Gotlieb SLD. Probabilidade de morrer no primeiro ano de vida em area urbana da regiao sul, Brasil. Rev Saude Publica 1993;27:445-54.

37. Morais Neto OL, Barros, MBA. Fatores de risco para mortalidade neonatal e pos neonatal n Regiao Centro oeste do Brasil: linkage entre banco de dados de nascidos vivos e óbitos infantis. Cad Saude Publica 2000;16:477-485.

38. Soares ES, Menezes GMS. Fatores associados à mortalidade neonatal precoce: análise de situação no nível local. Epidemiol Serv Saúde 2010;19:51-60.

39. UN Inter-agency Group for Child Mortality Estimation. Levels \& trends in child mortality: report 2019. New York:
UNICEF; 2019.

40. Blencowe H, Krasevec J, de Onis M, et al. National, regional, and worldwide estimates of low birthweight in 2015, with trends from 2000: a systematic analysis. Lancet Glob Health 2019;7:e849-e860.

41. Chawanpaiboon S, Vogel J, Moller A, Lumbiganon P, Petzold M, Hogan D, et al. Global, regional, and national estimates of levels of preterm birth in 2014: a systematic review and modelling analysis. Lancet Glob Health 2019;7:e37-e46.

42. Blencowe H, Cousens S, Oestergaard M, Chou D, Moller A, Narwal R, et al. National, regional, and worldwide estimates of preterm birth rates in the year 2010 with time trends since 1990 for selected countries: A systematic analysis and implications. Lancet 2012;379:2162-72.

43. Morgan MC, Spindler H, Nambuya H, et al. Clinical cascades as a novel way to assess physical readiness of facilities for the care of small and sick neonates in Kenya and Uganda. PLoS One 2018;13:e0207156.

44. Conde-Agudelo A, Diaz-Rosello J. Kangaroo mother care to reduce morbidity and mortality in low birthweight infants. Cochrane Database Syst Rev 2016;23:CD002771.

45. Medvedev MM, Tumukunde V, Mambule I, et al. Operationalising kangaroo Mother care before stabilisation amongst low birth Weight Neonates in Africa (OMWaNA): protocol for a randomised controlled trial to examine mortality impact in Uganda. Trials 2020;21:126.

46. Abreu LC. Integrated actions and strengthening of Public Health System in Brazil in a time of pandemic. J Hum Growth Dev 2020;30:5-8.

47. Bastos JL, Dumith SC, Santos RV, Barros AJ, Del Duca GF, Gonçalves H, Nunes AP. Does the way I see you affect the way I see myself? Associations between interviewers' and interviewees' 'color/race' in southern Brazil. Cad Saude Publica 2009;25:2111-24.

48. Antunes J, Toporcov TN, Biazevic MG, et al. Gender and racial inequalities in trends of oral cancer mortality in Sao Paulo, Brazil. Rev Saude Publica 2013;47:470-8.
Cite this article as: de Oliveira AG, Macedo H Jr, Santos EFS, Leone C, Leitão FNC, Pimentel RMM, de Abreu LC, Wajnsztejn R. Early neonatal mortality trend in adolescent pregnant women in the State of São Paulo, Brazil, from 1996 to 2017. Transl Pediatr 2021;10(6):1573-1585. doi: 10.21037/tp20-438 